\title{
The S-O clip closure method: a novel method for closing large mucosal defects
}

The S-O clip (Zeon Medical Co., Ltd., Tokyo, Japan) is a traction device designed for endoscopic submucosal dissection (ESD) $[1,2]$. We report a case of successful closure of a large mucosal defect using $\mathrm{S}$-O clips after an endoscopic submucosal resection (EMR).

A 78-year-old man was treated with EMR for a sessile serrated adenoma/polyp over $20 \mathrm{~mm}$ in size in the ascending coIon ( $\mathbf{F i g . 1 a ) . ~ T h e ~ s u r g e r y ~ r e s u l t e d ~ i n ~ a ~}$ large mucosal defect (> Fig.1b). We planned to close it using S-O clips to prevent bleeding and perforation.

First, two S-O clips were connected to the edge of the wound facing each other ( Fig.2a). Second, the loop of the proximal-side S-O clip was connected to the distal side of the colon mucosa with an endoscopic clip ( $>$ Fig.2b). The same procedure was repeated for the distal side S-O clip ( $\mathbf{F i g . 3}$ ). Thus, the opposite sides of the wound margin were connected and the area of the mucosal defect was reduced ( $\triangleright$ Video $\mathbf{1}$ ). In addition, the site was elevated by the traction effect of the S-O clip. Regular clips were placed individually to achieve complete closure. Finally, the loop of the S-O clip was resected with a loop cutter. Complete tissue apposition was observed ( Fig.4).

Choice of available methods of tissue apposition for large mucosal defects with single-channel endoscopy [3-5] depends on the operator and facility capabilities. Our technique has the advantages of being easy to perform, and elevation of the site associated with the traction effect makes it easier to achieve complete closure, even with very large mucosal defects and endoscopic perforations. Although we used two S-O clips in this case, one is probably sufficient in most cases to achieve complete tissue apposition.

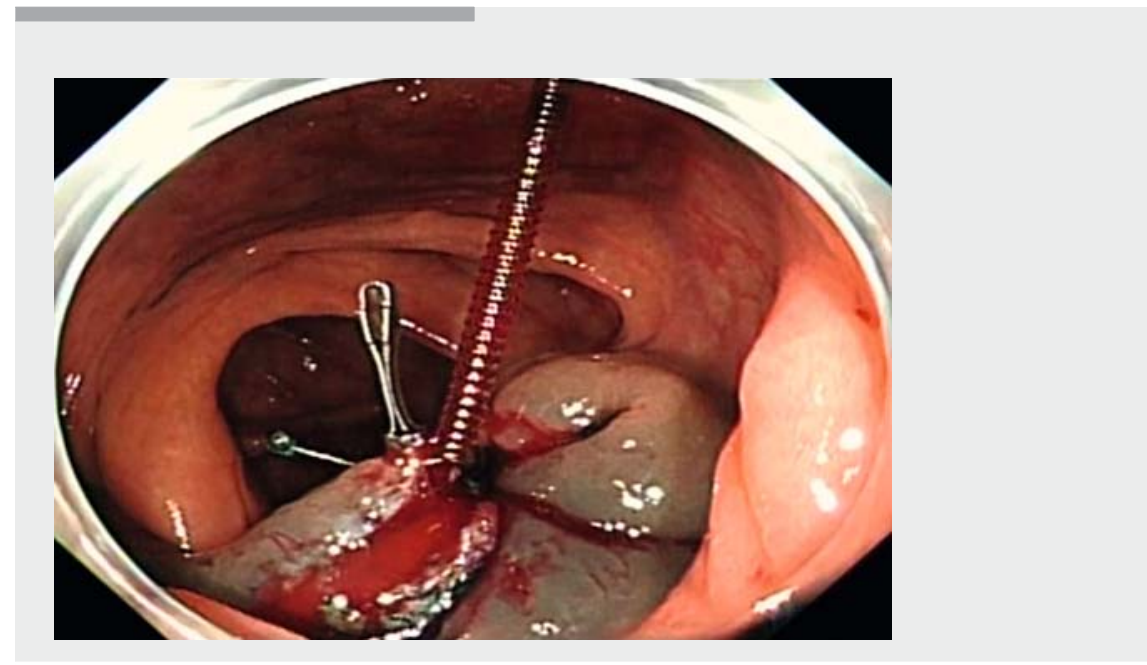

$\checkmark$ Video 1 The proximal and distal side S-O clips are crossed, the opposite side of the wound margin is connected, and the area of the mucosal defect is reduced.

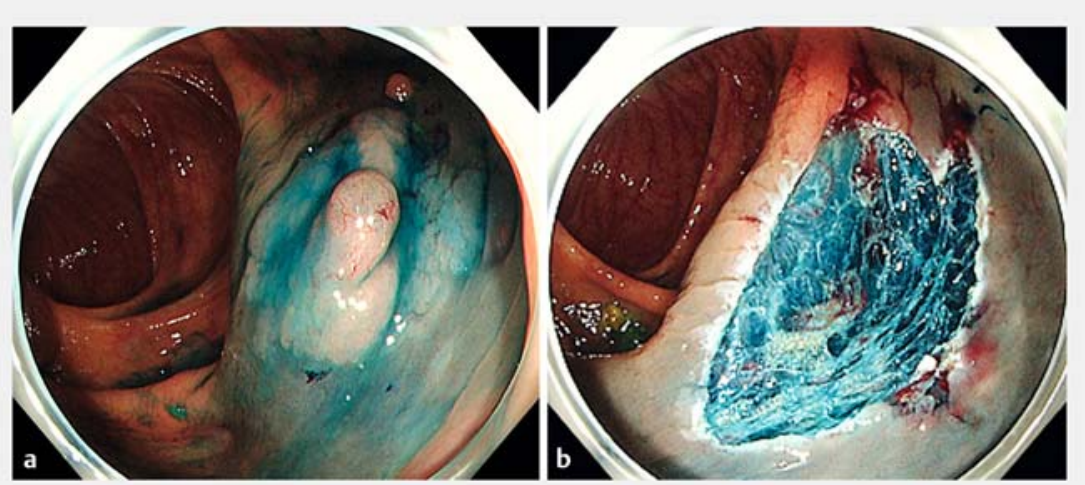

- Fig. 1 a A lager sessile serrated adenoma/polyp. b A large mucosal defect seen after endoscopic submucosal resection. 


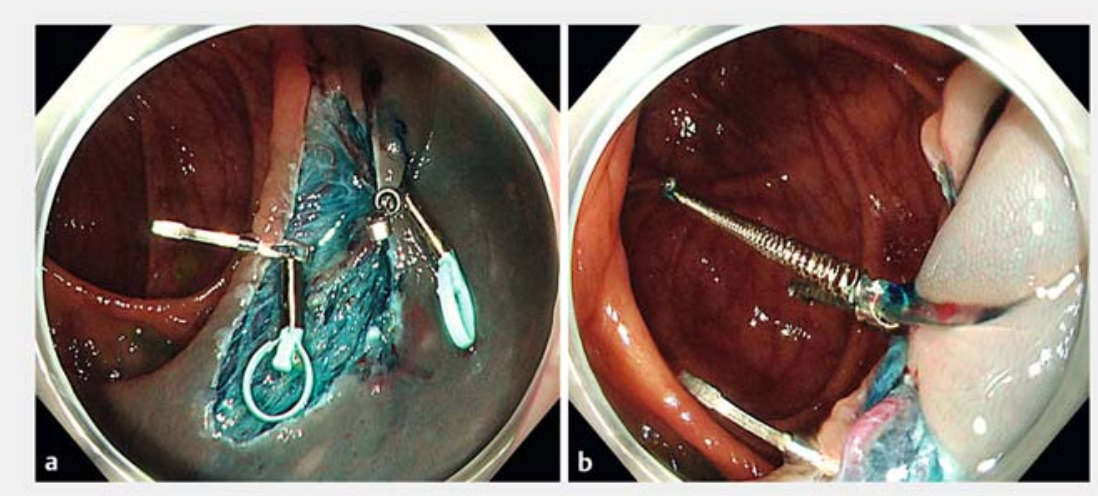

Fig. 2 a Two S-O clips connected to the edge facing each other. b The proximal-side S-O clip connected the distal side of the colon mucosa.

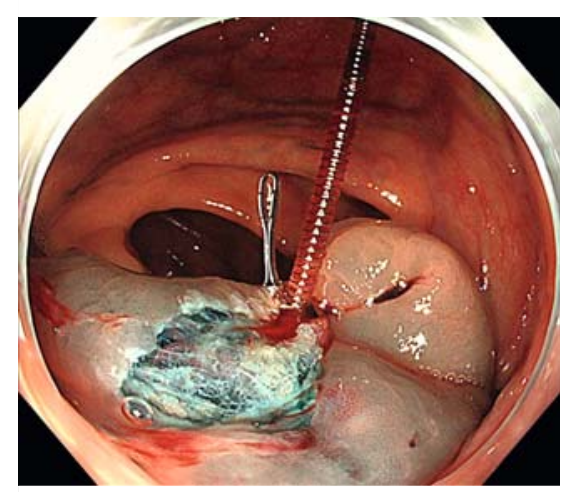

- Fig. 3 The distal-side S-O clip connected the proximal side of the colon mucosa. The site is elevated by the traction effect of the S-O clip.

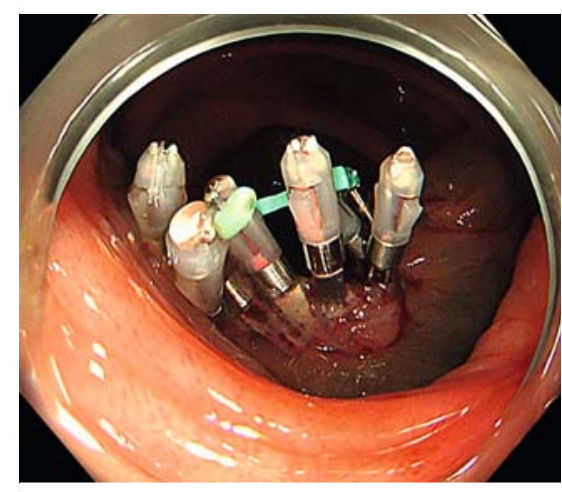

- Fig. 4 Complete tissue apposition has been achieved.
Competing interests

The authors declare that they have no con-

The authors

Tsuyoshi Suda, Tomohide Omizo, Takuya Seike, Naoki Oishi

Department of Gastroenterology, Kanazawa Municipal Hospital, Kanazawa Ishikawa, Japan.

\section{Corresponding author}

\section{Tsuyoshi Suda, MD}

Department of Gastroenterology, Kanazawa Municipal Hospital, 3-7-3, Heiwamachi, Kanazawa, Ishikawa 921-8105, Japan Fax: +81762452690

t.suda1112@gmail.com flict of interest.

\section{References}

[1] Sakamoto N, Osada T, Shibuya T et al. The facilitation of a new traction device (S-O clip) assisting endoscopic submucosal dissection for superficial colorectal neoplasms. Endoscopy 2008; 40: E94-E95

[2] Hashimoto R, Hirasawa D, Iwaki T et al. Usefulness of the $\mathrm{S}$-O clip for gastric endoscopic submucosal dissection (with video). Surg Endosc 2018; 32: 908-914

[3] Akimoto T, Goto O, Sasaki M et al. "Holdand-drag” closure technique using repositionable clips for large mucosal defects after colonic endoscopic submucosal dissection. Endosc Int Open 2016; 4: 1068-1072

[4] Sakamoto N, Beppu K, Matsumoto K et al. "Loop Clip", a new closure device for large mucosal defects after EMR and ESD. Endoscopy 2008; 40: E97-E98

[5] Zeng CY, Li GH, Zhu Y et al. Single-channel endoscopic closure of large endoscopyrelated perforations. Endoscopy 2015; 47: 735-738

\section{Bibliography}

DOI http://dx.doi.org/10.1055/a-1191-2863

Endoscopy International Open 2020; 08: E1163E1164

(c) Georg Thieme Verlag KG

Stuttgart $\cdot$ New York

elSSN 2196-9736

\section{(ㄷ) (1) $(-) \div$}

